\title{
An SHTB-based experimental technique for elevated temperature
}

\author{
Chen Xuan ${ }^{1 \mathrm{a}}$, Li Yulong ${ }^{2 \mathrm{~b} *}$, Ouyang $\mathrm{Na}^{3 \mathrm{c}}$ \\ ${ }^{1}$ School of Aeronautics, Northwestern Polytechnical University, Xi'an, China \\ ${ }^{2}$ School of Aeronautics, Northwestern Polytechnical University, Xi'an, China \\ ${ }^{3}$ School of Language, Literature and Law, Xi'an University of Architecture and Engineering, Xi'an, \\ China
}

Chenxuan186@gmail.coma ${ }^{\mathrm{a}}$ liyulong@nwpu.edu.cn ${ }^{\mathrm{b}}$, joannaouyang@gmail.com ${ }^{\mathrm{c}}$

\begin{abstract}
Keywords: SHTB; elevated temperature; Simultaneous-Heating-and-Cooling (SHC);2D C/SiC composite; SEM
\end{abstract}

\begin{abstract}
A new experimental technique by means of split Hopkinson tensile bar (SHTB) at elevated temperature of $800^{\circ} \mathrm{C}$ was introduced. By this technique we carried out an investigation into the dynamic properties of $2 \mathrm{D} \mathrm{C} / \mathrm{SiC}$ composite at both room and elevated temperature of $20^{\circ} \mathrm{C}$ and $800^{\circ} \mathrm{C}$. It was found that the failure strength and strain of $2 \mathrm{D}-\mathrm{C} / \mathrm{SiC}$ composite decreases significantly with the increase of temperature. Observation of SEM micrographs of failed specimen fracture under dynamic tensile loading at both temperatures reveals a comparatively smooth fracture and short fiber pull-out at elevated temperature of $800^{\circ} \mathrm{C}$, and we attribute it to the oxidation or partial oxidation of the carbon fibers under dynamic loading at elevated temperature.
\end{abstract}

\section{Introduction}

In recent years, people began to turn considerable attention to the dynamic behavior of engineering materials in extreme circumstances like elevated temperatures and high strain rates. Though Hopkinson bar has been widely applied to determine the dynamic properties of materials like metal [1] and composite [2] materials etc. dynamic experimentation at elevated temperature has always been a technique difficulty. Efforts have been made ever since 1960's in a few laboratories in terms of the dynamic pressure tests at elevated temperature of around $600^{\circ} \mathrm{C}$ by means of Split Hopkinson Pressure Bar (SHPB) [3]. Related researches by Yulong Li, etc. have also been conducted by elevating the experimental temperature to $1000^{\circ} \mathrm{C}$ [4].

Though SHPB experimental technique at elevated temperature has already been achieved, SHTB experimental technique at temperatures of above $600^{\circ} \mathrm{C}$ has been hardly reported home and abroad and thus still remains a problem to tackle. Owing to the fact that the specimen is fixed to the bars, the SHPB experimental technique at elevated temperature can not be simply copied and applied to dynamic tensile experiments.

A new experimental technique by means of Hopkinson tensile bar at elevated temperature of $800^{\circ} \mathrm{C}$ will be introduced in our present work to investigate into the dynamic behavior of $2 \mathrm{D} \mathrm{C} / \mathrm{SiC}$ composites.

\section{Hopkinson Tensile Bar Experimental Technique at Elevated Temperature}

\section{Experimental Setup.}

A new Simultaneous-Heating-and-Cooling (SHC) system is added to the traditional Hopkinson tensile bar, as shown in Fig. 1. The SHC system consists of an electro-thermo furnace, split cooling chambers, and a temperature controlling system. As mentioned in the previous section, the specimen tested by means of SHTB at elevated temperature can not be heated separately from the elastic bars as in classic SHPB experiments at elevated temperature, in which the simultaneous assembling technique can be employed when the specimen has been properly heated to the desired temperature. In this view, a new SHC apparatus was especially designed. Our main concern here is to work on the heat-insulation and refrigeration of the elastic bars and the connecting part between the specimen and 
the elastic bars, as schematically shown in Fig. 2. It is noted that the utmost distance between the end of the incident bar and transmitted bar is only $20 \mathrm{~mm}$, allowing for a rather limited space for the whole heating and cooling process.

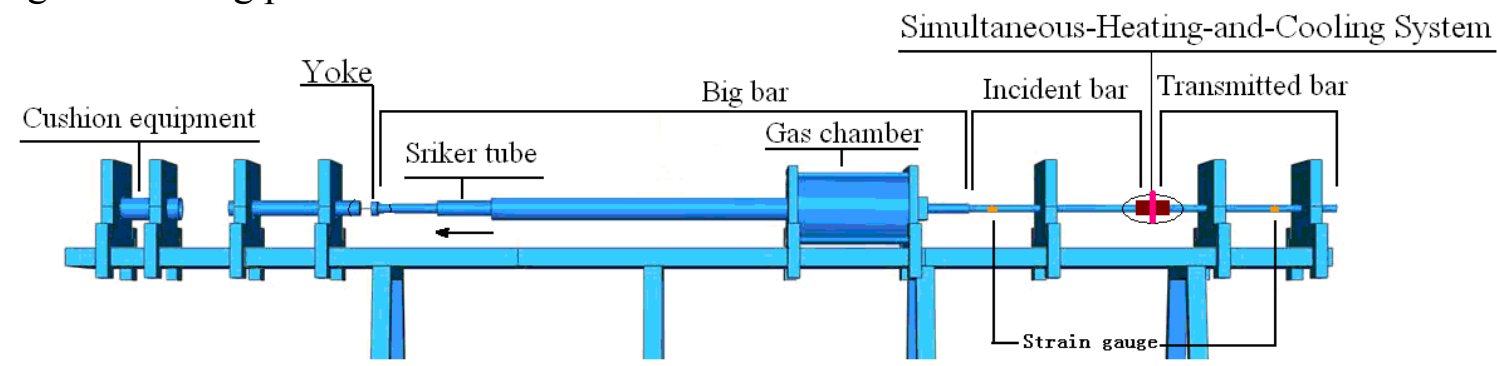

Fig.1 SHTB setup for elevated temperature experiment.

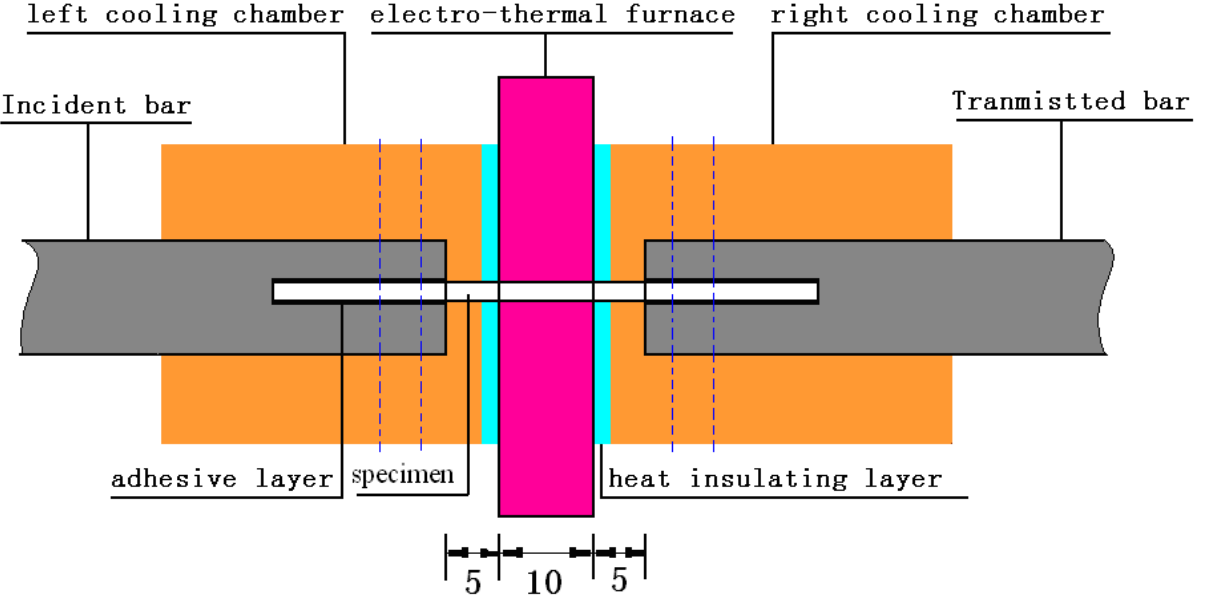

Fig. 2 Simultaneous-Heating-and-Cooling (SHC) apparatus:

As the name suggests, SHC system comprises of both a heating and cooling system. A mini-size electro-thermo furnace was designed to heat to specimen to the target temperature of $800^{\circ} \mathrm{C}$, and two cooling chambers were meant to refrigerate the elastic bars and connecting part between the specimen and the bars, so that the temperature of elastic bars be kept well below their quenching temperatures (The incident steel bar has a quenching temperature of $400{ }^{\circ} \mathrm{C}$, and the transmitted aluminum bar $200^{\circ} \mathrm{C}$ ). Besides, a heat insulating layer was employed to minimize the heat exchange between the electro-thermo furnace and the cooling chamber. It has to be made clear that the specimen in our experiment is bonded to the elastic bars by heat-resistant epoxy DG-3S with a heat-resistant temperature of mere $250^{\circ} \mathrm{C}$, which is a far from the target experimental temperature. Thus, the refrigeration and heat insulation become vital to our experiment.

\section{Experimental Method.}

The SHCS was assembled prior to SHTB tests. When a stable target temperature of specimen was reached, the gas released from the gas chamber propelled the striker tube that impinged on the free end of the yoke, thus a compressive pulse was first generated in the yoke by the impact of the striker tube. The compressive pulse was then converted to a tensile pulse in the free surface of yoke. The tensile pulse propagated back along the big bar, then the incident bar. Some of the incident pulse was reflected back into the incident bar from the input bar-specimen interface. The other part of the incident pulse was transmitted through the specimen into the transmitted bar. Strain gauges mounted on the incident and transmitted bar measured the incident, reflected and transmitted pulses. One-dimensional elastic wave equation was then used to obtain stress, strain and strain rate of the sample [5]. The schematic of SHTP setup is illustrated in Fig. 1, 


$$
\left\{\begin{array}{l}
\sigma_{s}=E_{b}\left(\frac{A_{b}}{A_{s}}\right) \varepsilon_{t} \\
\dot{\varepsilon}=-\left(\frac{2 C}{l}\right) \varepsilon_{r} \\
\varepsilon=-\left(\frac{2 C}{l}\right) \int \varepsilon_{r} d t
\end{array}\right.
$$

where $\sigma_{s}, \mathcal{E}$ stand for the stress and strain of the specimen, $\mathcal{E}_{r}, \mathcal{E}_{t}$ the reflected and transmitted strain, $C$ the longitudinal wave speed of the bar, $A_{b}, E_{b}$ the traverse area and elastic modulus of the bar, $l, A_{s}$ the length and the traverse area of the specimen, respectively.

\section{Material Preparation}

The 2D-C/SiC composite employed in our work was supplied by the National Key Laboratory of Science and Technology on Thermostructure Composites Materials in Northwestern Polytechnical University, People's Republic of China. The composite tested in the present investigation was prepared by chemical vapor infiltration of $\mathrm{SiC}$ into $2 \mathrm{D}$ fabricated performs consisting of stacks of T300-1K carbon fiber woven fabrics laminated in plane direction, with each layer oriented at $90^{\circ}$ with the adjacent cloth. The average thickness of the woven fabrics was $0.16 \mathrm{~mm}$. Before infiltration, the carbon fiber was deposited with pyrolytic carbon interfacial layer with the average thickness of 100-200 $\mathrm{nm}$. In this way, the resultant composite had a fiber volume fraction of approximately $45 \%$ and a porosity of 5-8\%. The composite material was machined into flat dog bone shaped specimens, and coated with $\mathrm{SiC}$ oxidation resistance layer with a thickness of $0.1-0.2 \mathrm{~mm}$. The density of specimen was $2.05 \mathrm{~g} / \mathrm{cm} 3$ and thickness $2 \mathrm{~mm}$. The $2 \mathrm{D}-\mathrm{C} / \mathrm{SiC}$ composite specimen prior to dynamic testing is shown in Fig. 3.

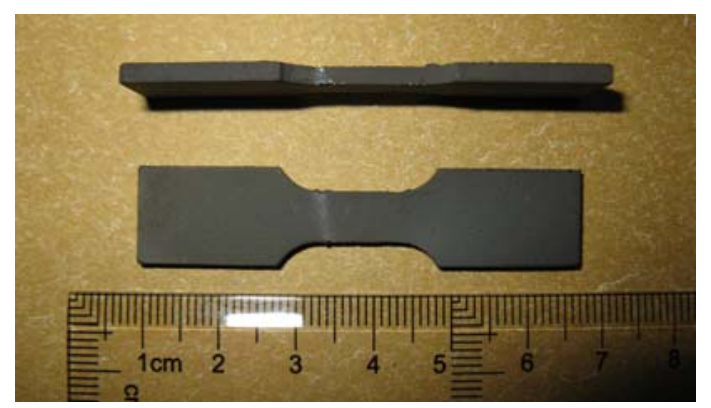

Fig.3 2D-C/SiC composite specimen.

\section{Results and Discussion}

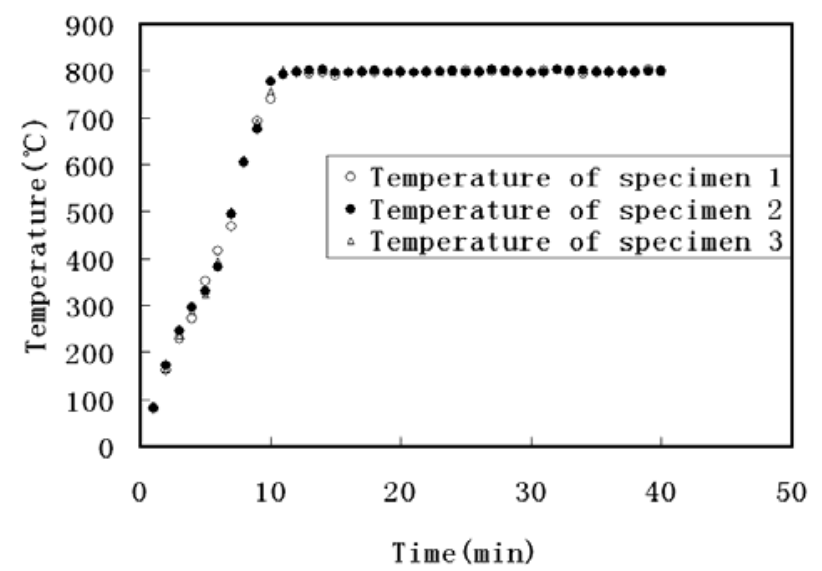

Fig. 4 Temperature profile of specimens tested at $800^{\circ} \mathrm{C}$.

Experiments on $2 \mathrm{D}-\mathrm{C} / \mathrm{SiC}$ at both room and elevated temperature of $20^{\circ} \mathrm{C}$ and $800^{\circ} \mathrm{C}$ by means of 
SHTB were conducted. It was found that the specimen's temperature approximated $800^{\circ} \mathrm{C}$ in eleven minutes. The specimen's temperature was then allowed to stabilize for another $30 \mathrm{~min}$ which brought the total heating process to about $40 \mathrm{~min}$. The variation of the specimen's temperature was kept within the range of $\pm 4^{\circ} \mathrm{C}$. Figure 4 shows the results of three different specimens. Fig. 5 shows the temperature variation at the connecting ends of the bars, where it was found that the temperature of the incident bar end reached its highest of $66^{\circ} \mathrm{C}$ in 11 minutes and remained at around $57^{\circ} \mathrm{C}$ in 13 minutes and afterward. Also the temperature of the transmitted bar end reached its highest of $104^{\circ} \mathrm{C}$ in 11 minutes and remained at around $66^{\circ} \mathrm{C}$ in 14 minutes and afterward. In other words, the temperature of the connecting part of the bars were well below it quenching temperature, thus would not lower its yielding limits. In this sense, the alteration in the natural impedance of the bars due to temperature variation can be disregarded [4].

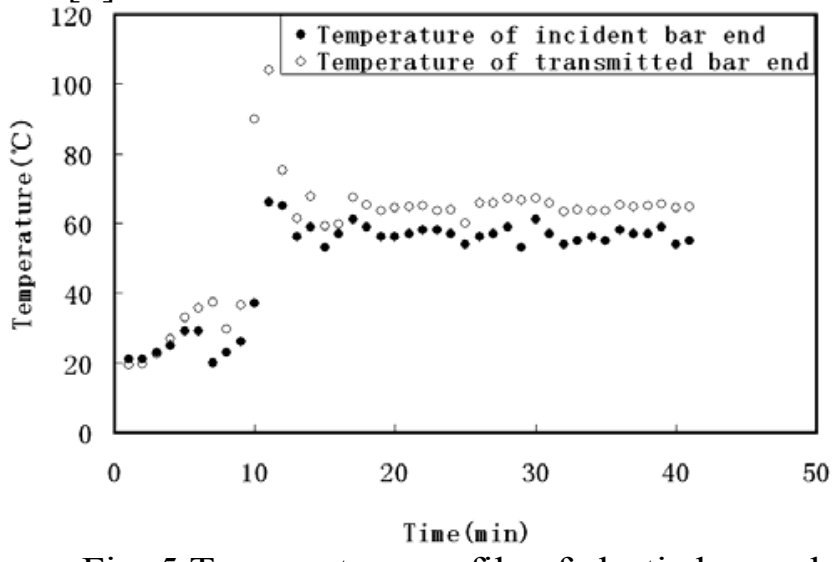

Fig. 5 Temperature profile of elastic bar ends.

The stress-strain waves of $2 \mathrm{D}-\mathrm{C} / \mathrm{SiC}$ composites at room and elevated temperature of $20^{\circ} \mathrm{C}$ and $800^{\circ} \mathrm{C}$ under dynamic tensile loading are given in Fig. 6, where an evident temperature-dependence can be observed. The failure strength and strain decreases significantly with the increase of temperature. To be exact, the strength decreased from an average of $308 \mathrm{MPa}$ to $260 \mathrm{MPa}$ and the strain from an average of $0.98 \%$ to $0.83 \%$, which was further verified by the SEM micrographs of failed specimens at room and elevated temperature of $20^{\circ} \mathrm{C}$ and $800^{\circ} \mathrm{C}$ under dynamic tensile loading in Fig. 7. It was found that the fracture surface was rough, with longer fiber pull-out $\left(70.56^{\mu m}\right)$ at room temperature, and comparatively smooth, with shorter fiber pull-out $\left(37.75^{\mu \mathrm{m}}\right)$ at elevated temperature. This was attributed to the difference in the thermo coefficient of matrix and fiber, giving rise to a quantity of micro-cracks in the matrix that serves as air transmission channels, thus resulting in the consequent oxidation of the carbon fibers and PyC interface layer at elevated temperature[6]. It has to be further pointed out that the oxidation or partial oxidation of the carbon fibers under dynamic loading at elevated temperature led to more brittle fibers and the lessened toughening and reinforcing effect, which were embodied in the decreases of failure strain with the increase of temperature.

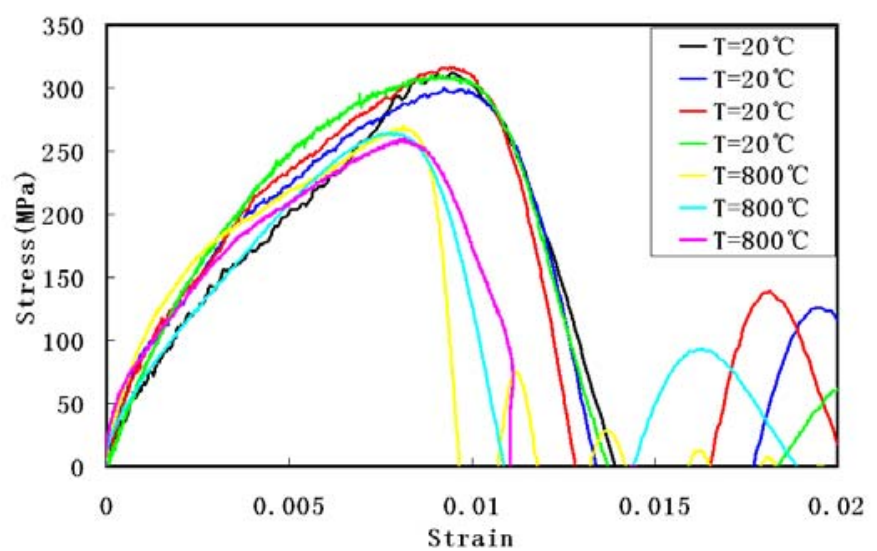

Fig. 6 The stress-strain curves of $2 \mathrm{D}-\mathrm{C} / \mathrm{SiC}$ composite at $20^{\circ} \mathrm{C}$ and $800^{\circ} \mathrm{C}$ under dynamic tensile loading. 


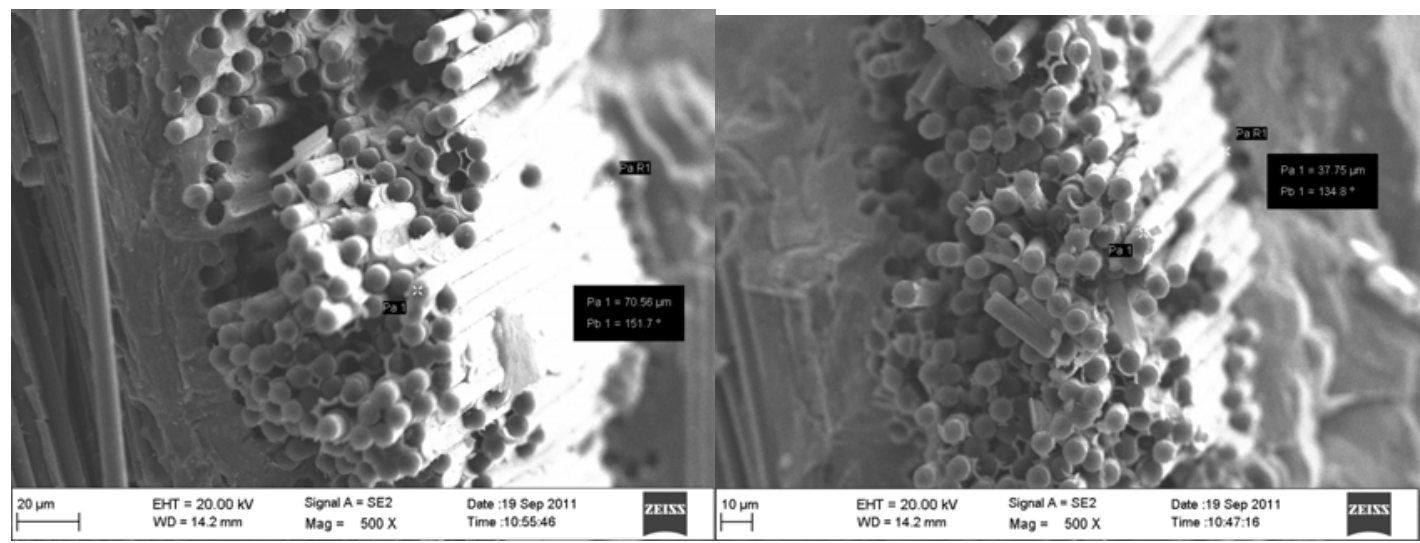

(a) $20^{\circ} \mathrm{C}$

(b) $800^{\circ} \mathrm{C}$

Fig. 7 The SEM micrographs of fracture surface: (a) $20^{\circ} \mathrm{C}$; (b) $800^{\circ} \mathrm{C}$.

\section{Conclusions}

A new experimental technique by means of Hopkinson tensile bar at elevated temperature of $800^{\circ} \mathrm{C}$ was introduced. By this technique we carried out an investigation into the dynamic properties of $2 \mathrm{D} \mathrm{C} / \mathrm{SiC}$ composite at both room and elevated temperature of $20^{\circ} \mathrm{C}$ and $800^{\circ} \mathrm{C}$. It was found that the failure strength and strain of $2 \mathrm{D}-\mathrm{C} / \mathrm{SiC}$ composite decreases significantly with the increase of temperature. Observation of SEM micrographs of failed specimen fracture under dynamic tensile loading at both temperatures reveals a comparatively smooth fracture and short fiber pull-out at elevated temperature of $800^{\circ} \mathrm{C}$, and we attribute it to the oxidation or partial oxidation of the carbon fibers under dynamic loading at elevated temperature.

\section{Acknowledgements}

The authors would like to acknowledge the financial support from the National Natural Science Foundation of China under the contract \# 10932008, 10902090, 11102168, and the 111 project of PR China under contract \# B07050.

\section{Reference}

[1]L. Djapic Oosterkamp, A. Ivankovic , G. Venizelos. Materials Science and Engineering A278 (2000) 225-235

[2]Mohd Firdaus Omar, Hazizan Md Akil , Zainal Arifin Ahmad , A.A.M. Mazuki , Takashi Yokoyama. Materials and Design 31 (2010) 4209-4218.

[3]L indholm U S. J. Mech. Phys. Solids, 1964, 12: 317-335

[4]Yulong Li ,Suo Tao, Weiguo Guo, Rui Hu, Jinshan Li, Hengzhi Fu. EXPL0S10N AND SH0CK W AVES. 2005 26(6) 487-492.

[5]H. Kolsky. Proc. Phys. Soc. 1949, B 62, 676-700.

[6]XU Yongdong, CHENG Laifei, ZHANG Litong, et al. Journal of the Chinese Ceramic Society, 2002, 30 (2): 184- 188. ( in Chinese) 